\title{
Low Family and High Substances Satisfaction as Important Predictors of Adolescent Hashish Use ${ }^{\#}$
}

\author{
Costas N. Katachanakis ${ }^{1}$, Maria P. Lambraki* ${ }^{*, 3}$ and Nicholas C. Paritsis ${ }^{1,2}$ \\ ${ }^{I}$ Department of Psychiatry and Behavioural Sciences, Division of Medicine, University of Crete, Stavrakia, Iraklion, \\ Crete, Greece; ${ }^{2}$ Society for Systems Therapy and Intervention, Athens, Greece; ${ }^{3}$ Youth Consulting Centre, Prefecture of \\ Iraklion, Crete, Greece
}

\begin{abstract}
Aims: We investigated the hypothesis, that hashish use among adolescents is strongly related to low levels of satisfaction at home within the family and high gratification from substance usage.

Methods: A survey was conducted among 1406 students whose ages ranged from 15 to 22 years old. More specifically, the students all from 16 different Secondary Schools, located on the island of Crete, Greece, were asked to anonymously complete a questionnaire, which referred to their family relations, family size, and substance usage. Hierarchical analysis was used.

Results: It was found that in hashish users, there is 2.5 times less family satisfaction $(\mathrm{p}=0.002)$, including the absence of both parents from home $(\mathrm{p}=0.03$ ) and 9 times more substance satisfaction (smoking $\mathrm{p}=0.001$, and consumption of alcohol $\mathrm{p}=0.026$ ) compared to non users.

Conclusions: There is a low family satisfaction and high satisfaction from smoking and alcohol characterizing hashish's users. The present findings may have implications for the prevention and intervention in hashish use by adolescents.
\end{abstract}

Keywords: Hashish use, substance use, family factors, prevention, intervention.

\section{${ }^{\#}$ This paper is dedicated to the memory of the deceased late Professor of Biostatistics John Vlachonikolis, for his valuable contribution to the design of this research.}

\section{INTRODUCTION}

Hashish use in adolescents is related with school dropouts [1, 2, 3] and delinquency [3, 4]. In addition hashish use may be a contributing factor in the future use of illegal substances and engagement in illegal activities. The above implication poses serious concerns for adolescent hashish users and therefore, constitute imperative the identification of predicting factors for cannabis use.

Empirical findings have shown that hashish use in adolescence is related with family factors and substance use in general.

Concerning the family factors hashish use found to refer to:

- divorced parents [5, 6],

- poor relations with parents [7-11]

- lack of parental supervision and control on their adolescent children [12-19]

- lack of close and tender family relations [10-21],

- unaffectionate parental control [18]

- reduced maternal interest in the children's upbringing [22]

*Address correspondence to this author at the Youth Consulting Centre Department of Secondary Education. Prefecture of Iraklion, Averof 19 ( $2^{\text {nd }}$ floor), 71202, Iraklion, Crete, Greece; Tel: + 302810 281092:

E-mail: advise@otenet.gr
- alienation of father and son [7] and

- the users' perception that their fathers are not very loving and don't show them enough interest [23-24]

Furthermore, adolescents' use of hashish was found to be positively connected with

- the use of legal substances such as coffee, beer, wine, cigarettes, hard liquor $[10,25,26]$

- the use of other illegal substances [25, 27-28]

Concerning the relation of hashish use with other substances there are theoretical approaches that follow. However, concerning the family factors there are no theoretical approaches.

In particular, there are two theoretical approaches related to the extensive use of substances by hashish users.

The first is the theory of Stages of drug involvement the ory, of Denise Kandel and co-workers [25, 29-30]. According to this theory three specific stages of substance use were described by the researchers: a) use of alcohol, b) use of marijuana, and c) use of other illicit drugs. The researchers documented the role of alcohol and other drugs as a gateway to increased risk of excess use.

The second is the Sensation seeking theory [31]. This theory can explain the empirical findings that show a link between sensation seeking variables and drug use [32-35] 
About family factors there are no theoretical approaches. It would be very useful a theoretical interpretation about family factors and even more in combination with other substance use.

Interaction theory of motivation [36-37] considers an antagonism between the preference for satisfaction from human relations and the preference for satisfaction from non human agencies, such as substances.

Having in mind the interaction theory of motivation, the previously mentioned family factors of hashish use can be viewed as related, directly or indirectly, with lack of family satisfaction.

Taking the aforementioned into account, we make the hypothesis that hashish use in adolescents is to a large extent a combination of low family satisfaction and high satisfaction from other substance use, such as nicotine and alcohol.

The aim of this study is to make a first step toward testing the above hypothesis.

\section{MATERIAL AND METHODS}

\subsection{Sample}

In order to test the above hypothesis of the family versus substance satisfaction in adolescent hashish users, an epidemiological study was carried out among adolescents in secondary schools.

The sample came from a wider epidemiological research concerning a number of factors for hashish, cigarette smoking and alcohol consumption in high school.

For the present research, the sample included data from 16 secondary education schools (11 from the city of Iraklion, and 5 from the small towns of the prefecture of Iraklion out of 44 all together), on the island of Crete, Greece. The criterion of selecting these schools from the prefecture of Iraklion is that in previous research [10] these schools showed a high percentage of hashish use among pupils. The purpose for using this selection was to enrich the sample with more hashish users since we were interested not in the percentage of hashish users but in the factors affecting this use.

Taking into consideration the large size of target population, which is 5,625 pupils, in the 16 schools which participated in this study, it was decided to examine a smaller but representative sample in order to decrease the time of collection and examination of the questionnaires as well as the cost of research. Thus, computing a-priori sample size for multiple regression we took into consideration four parameters:

(1) The alpha level (also known as the p-value, probability, or type I error rate) $=5 \%$

(2) The number of predictors in the model (not including the intercept); when this study was being planned that number was 10 , but during the process it was reduced to 8 predictors.

(3) The anticipated effect size $=0.02$

(4) The desired statistical power level $=97.5 \%$ (By convention, a value greater than or equal to $80 \%$ considers adequate) [38].

Therefore, the Minimum Required Sample Size was 1406 pupils; almost a quarter of the population..
For the selection of those 1406 students, a Simple Random Sampling was conducted because it provides equal opportunity to each member in the population to be included in the sample. This is the best bias-free sampling technique if all the population members could be identified and labelled.

As mentioned above, the sample comprised of 1406 subjects (51.5\% boys, $48.5 \%$ girls), their average age being 17.5 years old (Standard Deviation 1.4). Nineteen cases were excluded ( $1 \%$ of the total sample) due to incorrect (in terms of erroneous questionnaire completion) and therefore the final sample consisted of 1387 students, of whom $758(54.7 \%)$ come from general high schools and 629 (45.3\%) come from technical schools. Technical schools usually consisted of working students. The number of pupils that make use of hashish was 183 (13.2\% of the total sample).

The present study examines the effect that family satisfaction and substances satisfaction (on the basis of substance use) have on the hashish users $(n=183)$ in comparison to the non-users $(n=1204)$ that did not. Regarding the students who use hashish, $68(37.2 \%)$ attend general high schools and 115 $(62.8 \%)$ attend technical schools $\left(\chi^{2}=26.026\right.$; d.f $=1$; $\mathrm{p}<0 . .001)$. Concerning gender, $710(51.6 \%)$ of the total sample were boys and 667 (48.4\%) were girls. Furthermore, the number of male cannabis users was $127(69.4 \%)$ and the number of female users was $56(30,6 \%)$ respectively. This difference was also statistically significant $\left(\chi^{2}=26.887\right.$; d.f $=1 ; \mathrm{p}<0.001)$.

Table 1 displays the responses of boys and girls, with regard to hashish use from the 16 schools that participated in the study. The responses to the questions concerning the use or non -use of hashish according to age groups appear in Table 2.

The difference that is observed between the use of hashish and age group to which each student belongs is statistically significant $\left(\chi^{2}=97.227\right.$; d.f $\left.=3 ; p<0.001\right)$. Specifically, there seems to be an increasing frequency of cannabis use as age increases.

\subsection{Instruments}

An inventory was used as measures of family satisfaction [39] together with the absence of both parents (as an indirect measure of lack of family satisfaction) As a measure of hashish use the question regarding "lifetime experience of hashish (even once)" was used. As a measure of satisfaction from substances cigarette smoking and alcohol consumption was used. Additionally, as confounding factors gender [3, 17, 26], and age [26-27] were used, which, according to the bibliography, are strongly related with the use of drugs. Socioeconomic status, as another confounding factor was not used. This was due to the results of our previous research [10], which took place among the same schools of the present research. The results showed that the socio-economic status (which was measured by the level of parental education) was not statistically related with hashish use.

A. The Family satisfaction scale [39] was used in order to assess family satisfaction. This scale was adapted and translated into Greek by a scientific team, after permission for translation and use was granted by the author of the scale. This team comprised a psychia- 
Table 1. Overview of the Data Collection in 16 Schools Participating in Survey

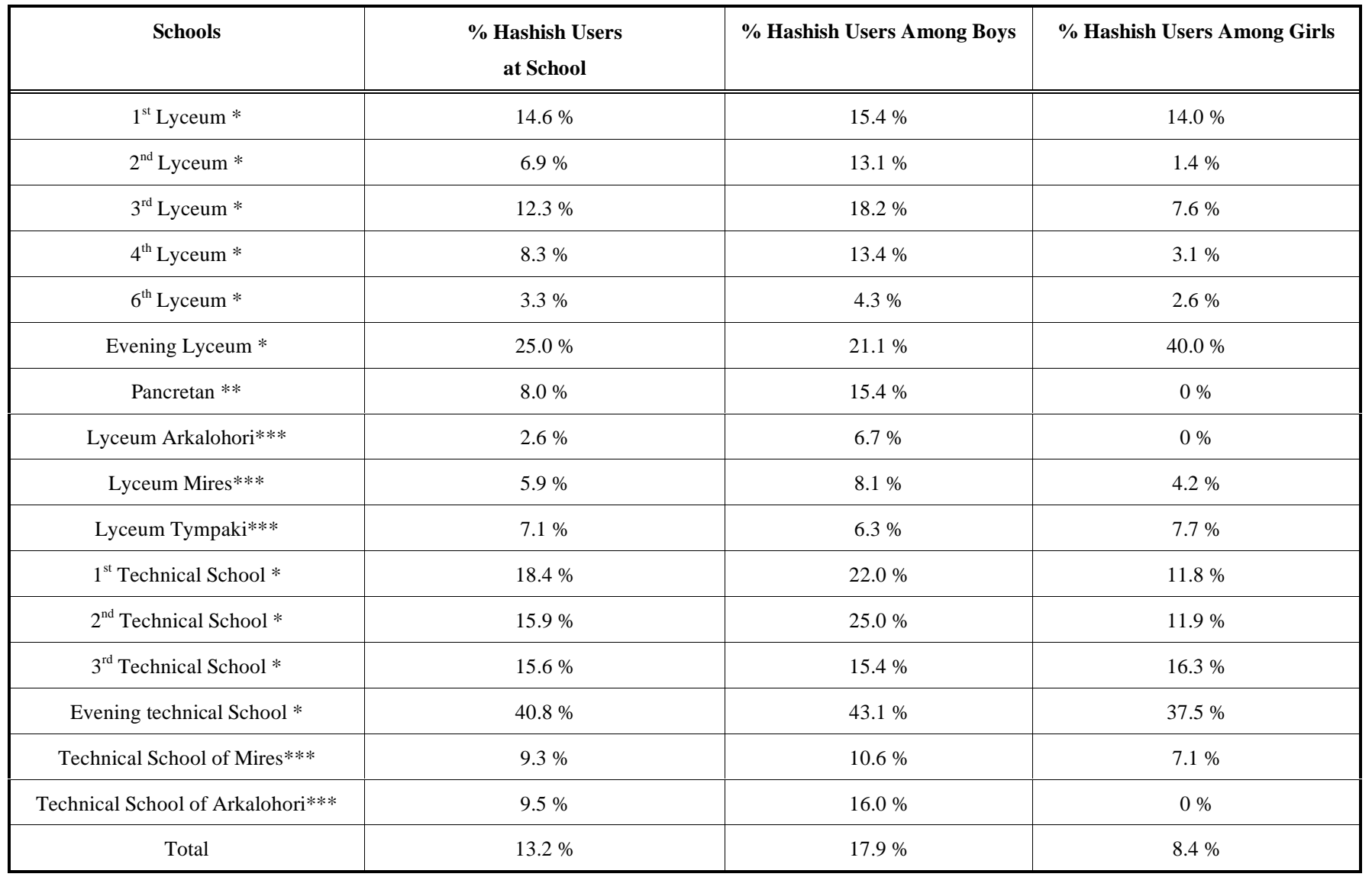

* Schools of Iraklion city

** Private schools of Iraklion city

*** Schools of prefecture

Table 2. Hashish Use According to Student's Age

\begin{tabular}{|c|c|c|}
\hline Age Groups & Non-Users (\%) & Hashish Users (\%) \\
\hline \hline $15-16$ & $368(95.1 \%)$ & $19(4.9 \%)$ \\
\hline $17-18$ & $663(87.4 \%)$ & $36(12.6 \%)$ \\
\hline $19-20$ & $120(78.9 \%)$ & $36(21.1 \%)$ \\
\hline $21+$ & $47(56.6 \%)$ & $183(13.3 \%)$ \\
\hline Total & $1198(86.7 \%)$ & $2 \%$ \\
\hline
\end{tabular}

trist, a psychologist, an English literature graduate and a Greek language high school teacher.

The scale included 14 questions with an answer range from "unsatisfied" to "very much satisfied" on a scale of 1 to 5. It consists of :

1) a "family cohesion" subscale of 8 items and

2) a "family adaptability" subscale of 6 items

The sum of the two subscales gives the total score.

Although the family satisfaction scale provides subscales for satisfaction on cohesion and adaptability, the total score is the most valid and reliable
B. Questions from a previous epidemiological study in Iraklion [10] were also used in order to assess:

\section{1). Smoking}

It was characterized as (a) non smokers, (b) occasional or regular smokers

\section{2). Consumption of alcohol during the last month}

It was the total sum of the variables: beer, wine or other alcohol-drinks. Rating as: (a) non drinking/ moderate drinking, including 0 times use, and 1-5 times drinking, (b) drinking, including $5+$ times drinking. 


\section{3). Use of other illegal substances}

The use one of the following: Opium, hallucinatory substances, cocaine or other non-legal substances.

\section{4). Absence of both parents [10]}

The questionnaire of the above epidemiological study in Iraklion [10] was used by the Institute Pompidou [40-42] for international research. This questionnaire was validated and it was used in European research. It was also used in Greece by Kokkevi [43].

\subsection{Method of Collecting the Data}

Prior to the collection of data the research proposal was submitted to an ethical committee of the Ministry of Education and after particular correction the committee gave us the permission to carry out this research.

The distribution and collection of the questionnaires was done by a specially trained team. This team consisted of Medical and Computer Science students. They were trained in :

Way of contact with schools' headmasters

Sample selection in each school

Questionnaires distribution, and

Questionnaires collection, as follows :

Following a telephone exchange with the headmasters of the selected schools, a date was set to carry out the research at each school. The research team randomly selected the $25 \%$ of the students (by giving a number to each students according to its position, and selecting a student every 4 number) that would participate in the research, which were informed on the purpose and the aim of the research. After the briefing the pupils that did not wish to participate withdrew from the study. The research team was present during the completion of the questionnaires in order to make any necessary clarifications. Each student who completed the questionnaire would leave it at a designated area, visible to all, without anybody being close enough to actually see the student's answers. In the end the completed questionnaires were shuffled in the presence of all before the research team collected them.

\subsection{Statistical analysis}

Differences between groups of students were examined using unpaired t-tests for: age, and Total Score of Family Satisfaction. Pearson's chi-square tests for contingency tables were performed for: gender, smoking status, alcohol consumption, parental presence and use of other illegal substances.

The relationship between hashish use and the other confounding factors mentioned above were studied by regression analysis. The data however did not satisfy the standard conditions of ordinary regression, as there is a hierarchical or multiple-level structure comprising units grouped at different levels. In fact, there is a 2-level structure, where students are the level-1 units and are grouped within schools (level-2 units).

Because of that hierarchical structure of the data, multilevel models were used to estimate the variance attributable to the school level (level 2) and the student level (level 1). It is expected, that students within the same school will be well differentiated (due to common cultural and economics factors etc, school environment), and this differentiation implies that this grouping and its members both influence and are influenced by the group membership. In other words, multilevel techniques were used to account for the clustering effect among pupils and schools. There is variability between individuals but also between schools, and if either of these sources of variability is not taken into account, it is most certain that wrong conclusions will be drawn [44]. In these cases, inefficient estimates and actual Type I error rates can greatly exceed the nominal rate [45]. Under these circumstances multilevel models compared to conventional models provide more accurate estimates of parameters and their standard errors.

From a computational point of view, multilevel modelling can be seen as a two-stage process. First, a separate individual level regression is defined for each school. Then, each of the school-specific co-efficients is modelled as a function of school variables. So, multilevel analysis allows the partition of the school-specific co-efficients: a fixed part that is common across schools and a random part varying between schools.

Therefore, in this study because of the hierarchical structure of data and the nature of the depended variable (Hashish Use is a dichotomous variable which takes two values 0 : for a non-user and 1: for a hashish user) a Multilevel Logistic Model is advisable to assess the influence of independent variables on the odds of being a hashish user.

Parameter estimation of the multilevel logistic regression model was conducted using the predictive quasi-likelihood method with second order Taylor expansion (PQL-2) [46] provided by MlwiN (version 2.0.008) software [47]. With PQL-2 both the fixed part and the random part of the model are approximated. Finally, the selection of the variables in the multilevel model was derived by the forward procedure.

Thus a two level model was used with students to be the level one unit and schools the level two units. A three level model (students grouped within classes within schools) was also tested, but the results were the same nevertheless.

\section{RESULTS}

The multi-level analysis indicated that seven out of eight factors which were finally investigated were associated with cannabis use (the results of the multi-level model are shown in Table 3 and the corresponding odds ratios in Table 4).

More specifically it appears that there is a positive crosscorrelation between hashish use and:

a) the use of substances such as cigarettes and alcohol

b) age

c) absence of both parents from the home

As can be seen from table 4, the odds of using hashish of a pupil who is smoking, are seven times greater than a student who has never smoked. Finally, students who have greater than usual alcohol consumption and those who live away from home are two and a half times more likely to use hashish in relation to other students who do not smoke, or 
Table 3. Hashish Use. Estimation of Parameters: Null Model (A), Full Model (B), Optimal Model (C)

\begin{tabular}{|c|c|c|c|c|c|c|c|}
\hline Parameter & \multicolumn{2}{|c|}{$\begin{array}{c}\text { (A) } \\
\text { Null Model }\end{array}$} & \multicolumn{2}{|c|}{$\begin{array}{c}\text { (B) } \\
\text { Estimate(s.e.) }\end{array}$} & \multicolumn{2}{|c|}{$\begin{array}{c}\text { (C) } \\
\text { Estimate (s.e.) }\end{array}$} & $\begin{array}{c}\text { p- } \\
\text { Value }\end{array}$ \\
\hline Constant $\left(\mathrm{a}_{0}\right)$ & -2.081 & $(0.197)$ & -8.781 & $(1.347)$ & -8.771 & $(1.349)$ & $<0.001$ \\
\hline Age & & & 0.345 & $(0.070)$ & 0.348 & $(0.070)$ & $<0.001$ \\
\hline \multicolumn{8}{|l|}{ Substance use } \\
\hline Smoking (Yes vs No) & & & 1.978 & $(0.254)$ & 1.983 & $(0.254)$ & $<0.001$ \\
\hline Alcohol consumption (Yes vs No) & & & 0.765 & $(0.347)$ & 0.790 & $(0.346)$ & 0.026 \\
\hline Use of other illegal substances & & & 0.184 & $(0.192)$ & & & \\
\hline Absence of both parents & & & 0.912 & $(0.431)$ & 0.935 & $(0.430)$ & 0.030 \\
\hline \multicolumn{8}{|l|}{ Random part: } \\
\hline${\sigma_{\mathrm{uo}}}^{2}$ : School level variance & 0.453 & $(0.215)$ & 0.143 & $(0.104)$ & 0.144 & $(0 . .105)$ & $<0.001$ \\
\hline
\end{tabular}

those who live with either both parents, or at least one parent.

In contrast, it appears that there is a negative crosscorrelation between cannabis use and
a) the female sex
b) the total Score of Family satisfaction

It is interesting to mention here, that male students have almost twice the odds than female students to use hashish (the corresponding Odds Ratio is 1.982) and also a healthy family environment (as it results from the high Total Score of Family Satisfaction) creates a "shield" against hashish use (negative Odds ratio value).

Table 4. The Odds Ratios (OR) as they were Produced by Multilevel Model

\begin{tabular}{|c|c|}
\hline Parameter & Odds Ratios \\
\hline \hline Age & 1.416 \\
\hline Genter (boy vs girl) & 1.982 \\
\hline Smoking & 7.265 \\
\hline Alcohol Consumption & 2.203 \\
\hline Total Score of Family Satisfaction & -0.975 \\
\hline Absence of Both Parents & 2.547 \\
\hline
\end{tabular}

\section{DISCUSSION}

According to the findings of table 4 about the odd ratios, smoking and alcohol consumption taken together are close to 10 times more in the hashish users than in non users.. This finding is in accordance with the theories of Stages of drug involvement theory of [25] and of Sensation seeking theory [31].

Furthermore, according to our finding of table 4 presenting the odd ratios, produced by the Multilevel model, the "absence of both parents" and "lack of family satisfaction" taken together are about 3,5 times more in hashish users than in the non- users. Absence of both parents may have several dimensions, but the lack of family satisfaction is an obvious and important one.

The findings concerning smoking and alcohol consumption, family satisfaction and absence of both parents in hashish users are in accordance to the assumptions of Interaction theory of motivation [36-37], and confirm our hypothesis.

The Interaction theory of motivation enriched the theories of Stages of drug involvement theory and of Sensation seeking theory by adding the idea of lack of satisfaction by human, family and/or social relations.

A question that arises, therefore, is the possible causal relation(s) between lack of family satisfaction and satisfaction from substances. Does the adolescent when not satisfied from human relations turns his interest to hashish and other drugs rather than seeking more fulfilling human relations? Or perhaps it is that after the adolescent receives a lot of satisfaction from drugs he or she loses the interest in satisfaction from family and human environment, or perhaps the relationship is circular?

The results of the present study did not exclude causal relations between low family satisfaction and use of substances and cannot confirm either such relations. The interaction theory of motivation implies a mutual antagonism (inhibition) between satisfaction from human relations and gratification from substance use. The results of our study leave this question unanswered. Unfortunately hierarchical analysis cannot answer that. 
Our group in order to investigate the first explanation we are presently conducting research through a randomized control trial by intervention only on adolescent's family and peer relations. If the hashish use is reduced then the causal relation between lack of family satisfaction and hashish use will be indicated.

The interaction theory of motivation considers and implies mutual inhibition between the motivation towards substance use and motivation towards satisfaction from human relations. Namely, in our case, there are circular causal relations between low family satisfaction and high substance satisfaction. The one induces the other.

There are many factors of hashish use in adolescence, apart from family reduced satisfaction and use of other substances.

The present study is a first attempt to investigate the relationship of hashish use with the combination of lack of satisfaction from family relations and satisfaction from other substances in adolescents.

A limitation of this study is that because of the investigation of a particular hypothesis concerning family satisfaction versus (or in comparison to) substance satisfaction did not include other variables related to other variables of human relations (e.g. friends, mates, ) and of substance use. This was the first attempt to test the satisfaction from human relations versus (or in comparison to) a more variety of substances. In addition relevant limitation is the absence of other known factors in the investigation that probably would show relations of the variables investigated in our study with other variable not included in the present study.

Future research can include more variables, such as those mentioned in the introduction that relate indirectly to lack of family satisfaction, and have been found in previous family studies, together with those related to general substance use. Such research would be worthwhile to be undertaken considering the findings of the present and previous studies. Furthermore, it would be of great importance for future research to take into account other forms of human relations and not only parental ones.

The present findings may be useful in informing parents and teachers in order to prevent adolescents from developing smoking and drinking habits which may predispose them to hashish. When the parents can be close to their children and offer a satisfactory family environment it's more likely that children will not seek satisfaction from hashish and substance use. That cigarette and alcohol drinking is harmful and family satisfaction is useful is well known, however this research show that the degree of predisposition to hashish use is extremely high and even more so, when combined with a no satisfying family environment.

The results of this study are expected to be useful also for family counseling, intervention and psychotherapy, in the cases of hashish use. Thus intervention has to include the restoration of satisfactory mother-father and parent-child relations towards a home with a satisfying atmosphere.

Interventions that are not directed to reduce smoking and alcohol use and not directed to induce satisfactory family and human relations in the hashish users, may have according to our findings, low probability of success towards eliminating hashish use. Most likely such methods of intervention no considering the findings of the present study, may allow the important causes to remain.

Further research on the issue for possible confirmation and utilization of the present findings are useful. Our group is already running a trial of intervention utilizing the present findings.

\section{CONCLUSIONS}

Low family satisfaction and high cigarette smoking and high alcohol consumption characterise adolescent cannabis users.

This may be indicative that in general satisfaction from family and human relations antagonises satisfaction from substance in general as interaction theory of motivation would consider. Of course, this needs to be further investigated in order to be accepted.

The findings of our study may have implications in the prevention, intervention and therapeutic actions toward cannabis use by adolescents.

Further research to confirm the present findings and to investigate possible generalizations would be useful.

Prevention, intervention and therapeutic research trials are very useful to test the validity and the practical value of the present findings.

\section{ACKNOWLEDGEMENTS}

This research was carried out with the permission and approval of the Ministry of National Education and Religion.

\section{REFERENCES}

[1] Hansen, J.B.; Toso, S.J. Gifted Child Today, 2007, 30(4), 30-41.

[2] Comiskey, C.M.; Miller, R.T.H. Young people, drug use and early school leaving, Submitted to the Research and Development Committee, The Department of Education and Science, Irish Life Building, Abbey St. Dublin1. Ireland. December 2000.

[3] Hochman, J.S.; Brill, N. Am. J. Psychiatry, 1973, 130(2), 132-140.

[4] Vulcano, B.; Barnes, G.; Langstaff, P. Int. J. Addict., 1990, 25(5), 531-544.

[5] Reynolds, I.; Rob, M. Med. J. Aust., 1988, 149, 250-56.

[6] Kyrre Breivik. J. Divorce \& Remarriage, 2006, 44(3 \& 4), 99-124.

[7] Schneider, R.; Kojak, G.; Ressdorf, H. J. Nerv. Ment. Dis., 1977 165(4), 269-274.

[8] Kokkevi, A.; Stefanis, K. Acta Psychiatr. Scand. Suppl., 1988 344(78), 151-157

[9] Selnow, G.W. J. Drug Educ., 1987, 17(4), 315-26.

[10] Dr. Lambraki, M. Thesis. University of Crete, Medical School, 1993 (in Greek.).

[11] Guxens, M.; Nebot, M.; Ariza, C.; Ochoa, D. Gac Sanit, 2007, 21(3), 252-60.

[12] Rield, L. J. Drug Educ., 1989, 19, 139-56.

[13] Beck, K. Am. J. Drug Alcohol Abuse, 1990, 16, 109-24.

[14] Steinberg, L.; Fletcher, A.; Darling, N. Pediatrics, 1994, 93(6), 1060-64.

[15] Stice, E. ; Barrera, M. ; Chassin, L. J. Abnorm. Child Psychiatry, 1993, 21, 609-29.

[16] Chilcoat, H. D.; Anthony, J. C. J. Am. Acad. Child Adolesc. Psychiatry, 1996, 35, 91-100.

[17] Bachman, J.; Johnston, L.; O’Malley, P. Am. J. Public Health, 1981, 71(1), 59-69.

[18] Torresani. S.; Favaretto, E.; Zimmermann, C. Compr. Psychiatry, 2000, 41, 123-9.

[19] Adalbjamardottir, S; Hafsteinsson, L. G. J. Res. Adolesc., 2001, 11, 4, 401-423.

[20] Tec, N. Adolescence, 1974, 9(35), 351-364.

[21] Pandina, R.G.; Schuele, J.A. J. Stud. Alcohol, 1983, 44, 950-973. 
[22] Cohen, C.; White, E.; Schoolar, J. Arch. Gen. Psychiatry, 1971, 24, 353-358.

[23] Brook, J.; Whiteman, M.; Gordon, A. J. Genet. Psychol., 1981, 138, 81-86.

[24] Brook, J.; Whiteman, M.; Gordon, A.; Brook, D. Genet. Psychol. Monogr., 1983, 108, 197-213.

[25] Kandel, D. Science, 1975, 190, 912-914.

[26] Shelley, E.; Wilson-Davis, K.; O'Rourke, F.; O'Rourke, A. Ir. Med. J., 1982, 75(7), 254-259.

[27] Mills, C.; Noyes, H. J. Consult. Clin. Psychol., 1984, 52(2), 231243.

[28] Newcomb, M.; Bentler, P. Addict. Behav., 1986, 11, 263-273.

[29] Kandel, D.; Faust, R. Arch. Gen. Psychiatry, 1975, 32, 923-932.

[30] Yamaguchi, K.; Kandel, D. Am. J. Public Health, 1984, 74, 668672.

[31] Zuckerman, M. In: Sensation seeking: beyond the optimal level of arousal. Hillsdale N.J. Ed. Lawrence Erlbaum, Assoc., 1979, pp. 268-299,

[32] Watten, R. Eur. Addict. Res., 1977, 3/4, 192-198.

[33] Pedersen, W.; Clausen, S.; Lavik, N. Acta Pshychiatr. Scand., 1989, 79(4), 386-390.

[34] Wood, P.; Cochran, J.; Plefferbaum, B.; Ameklev, B. J. Drug Issues, 1995, 25(1), 173-193.

[35] Teichman, M.; Barnea, Z.; Ravav, G. Br. J. Addict., 1989, 84(2), 181-190.

[36] Paritsis, N.; Stewart, D. In Improving the human condition: Quality and stability in social systems. Ericson, R. Ed. Society for General Systems Research, 1979, pp. 866-874.

[37] Paritsis, N.; Destounis, N.;. Dyn Psychiatry, 1982, 15, 227- 239
[38] Cohen, J.; Cohen, P. West, S.G.; Aiken, L.S. Applied Multiple Regression/Correlation Analysis for the Behavioral Sciences $3^{\text {rd }}$ ed. Lawrence Earlbaum Associates, Mahwah, NJ 2003

[39] OIson, D.H.; Wilson, M. Family Satisfaction. In: Family Inventories, Olson, D.; McCubbin, H.; Barnes, H.; Larson, A.; Muxan, M.; Wilson, M. Eds.; University of Minnesota, Minneapolis, 1982.

[40] Johnston, L.; Harrison, L. Results of a school-based drug use Survey of $7^{\text {th }}, 9^{\text {th }}$ and $12^{\text {th }}$ graders in a Midwestern American City. Meeting of the drug epidemiology expert group of the council of Europe's Pompidou group held in Stockcholm, September 15-17 1986.

[41] Driessen, F.M.; Van Dam, G. Results of a drug use Survey among students of secondary education in Amstredam. Paper prepared for the drug epidemiology expert group of the council of Europe. Amstredam, September 1988.

[42] Johnston L. Outline for country reports of school survey studies. For the expert committee on drug epidemiology. Pompidou group. Council of Europe, 1987.

[43] Kokkevi, A.; Madianou, A.; Stefanis, K. Drugs in Greece. Substance use among pupils' population. C. Psychiatric Library 1993.

[44] Snijders, TA.; Bosker, R.J. Multilevel analysis: An introduction to basic and advanced multilevel modeling, Sage, London 1999.

[45] Hox, J. Multilevel analysis: Techniques and applications. (Chp 6) Erbaum, Mahwah, NJ 2002 (Chapter 6).

[46] Goldstein, H.. Multilevel Statistical Models. 2nd ed. Edward Arnold, London 1995.

[47] Rasbash, J.; Browne, W.; Goldstein, H.; Yang, M.; Plewis, I.; Healy, M.; Woodhouse, G.; Draper, D.; Langford, I.; Lewis, T Auser's guide to MlwiN, 2nd ed. Institute of Education, London 2000.

(C) Katachanakis et al.; Licensee Bentham Open.

This is an open access article licensed under the terms of the Creative Commons Attribution Non-Commercial License (http://creativecommons.org/licenses/by-nc/3.0/) which permits unrestricted, non-commercial use, distribution and reproduction in any medium, provided the work is properly cited. 